\title{
Migración, espacio y exclusión en 2020 de Javier Moreno
}

\author{
Carolina Leon Vegas (Dalarna University, Suecia)
}

\begin{abstract}
A number of novels about the financial crisis and its consequences have been written in Spain in recent years. In most, migrants are represented in a secondary role, often as short allusions or as mere ornaments. This article aims to highlight one novel, 2020 by Javier Moreno, that breaks that pattern since it features migrant characters in key roles. The article further aims to analyse the relationship between space and the representation of the migrant in the context of a society in crisis. The notions of non-place by Marc Augé and heterotopia by Michel Foucault will serve as the theoretical framework that will allow for an exploration of phenomena such as the inversion of non-places into places, the connection of crisis and deviation, the role of certain spaces as both shelters and containers of the unwanted, the role of gaze in the construction of an exclusion, and the circular movement of powerless characters in time and space throughout the novel.
\end{abstract}

Keywords: Javier Moreno, crisis, space, migrant, non-place, heterotopia

\section{Introducción}

Los textos de ficción, a pesar de su nombre, tienden a recrear, de una u otra forma, el mundo en el que viven sus autores, sus preocupaciones, sus vivencias y, en no pocas ocasiones, su realidad social. Beatriz Celaya-Carrillo $(2011,344)$ señala la escasez de representaciones literarias de la inmigración en literatura y creemos que esto tiene que ver con el perfil predominante de los escritores y escritoras publicados en España: origen español y clase media. La tendencia a excluir a las clases más desfavorecidas en general y a la población inmigrante en particular, no puede más que confirmarse si miramos el corpus de las novelas escritas durante los últimos años en torno a las consecuencias de la crisis financiera de 2008. Bautizado como "literatura de la crisis" (Rodríguez Marcos 2013), este corpus se ha visto sometido a una serie de críticas en cuanto al posible carácter oportunista de su etiqueta. David Becerra por ejemplo escribe con una intención claramente crítica: "de pronto hemos pasado de la 'crisis de la novela' a la 'novela de la crisis'. De pronto, como una suerte de subgénero, se ha empezado a hablar de 'novelas de la crisis', con títulos más oportunistas que oportunos" (2015, 21). Por su parte, Pablo Valdivia propone substituir la etiqueta de "literatura de la crisis" por la noción de "literatura deshereda": "más que encontrarnos frente a una literatura de la crisis, nos hallamos ante una nueva literatura desheredada - de la misma manera que existe un nuevo sujeto histórico desheredado" $(2016,34)$. Valdivia se apoya en la definición de la RAE de «Pobre, que carece de medios de vida». Como participio de «desheredar», la palabra desheredado alude no solo a una pobreza sino a una privación de algo prometido, de algo a lo que uno tenía derecho. Esta noción describe a la perfección el fenómeno de la pérdida que es el denominador común a la mayor parte de la narrativa de la crisis, ya sea en forma de retratos del desempleo, del

ROM17 Edited by Jon Askeland, Marco Gargiulo and Synnøve Ones Rosales.

BeLLS Vol. 10, No. 1 (2019), DOI 10.15845/bells.v10i1.1456.

Copyright $\odot$ by the Author(s). Open Access publication under the terms of CC-BY-NC-4.0. 
desahucio o de la pérdida general de poder adquisitivo. Más allá de posibles críticas o discusiones en torno a su denominación, parece claro que en los últimos años se ha escrito una serie de libros que retratan una crisis y la situación de precariedad e inestabilidad que sobreviene con ésta.

Las crisis financieras suelen afectar de forma más contundente a los sectores menos favorecidos y, en la crisis española, esto no ha sido una excepción. En su informe International Migration Outlook 2014, la OCDE muestra las altas tasas de desempleo de la población inmigrante en comparación con la nacida en España lo cual señala a esta como uno de los grupos más duramente golpeados por la situación económica. La pregunta, por tanto, que guía este texto es cómo se representa a este sector, los inmigrantes, en la literatura contemporánea de los últimos años, en especial en la llamada "literatura de la crisis". Tras la lectura de un número de textos ${ }^{1}$ podemos ver que en muchas ocasiones más que un retrato, lo que se encuentra en las páginas de estos libros son alusiones. El libro Los ciervos llegan sin avisar, de Berna González Harbour, es un ejemplo de menciones esporádicas con una función anecdótica o decorativa. En el metro, por ejemplo, la narradora observa a "una pareja de latinoamericanos, tal vez bolivianos" que entra a pedir limosna "con crucifijos y estampas de la virgen en la mano" (2015, 32) y más adelante se hace alusión a una limpiadora mulata (60) y a prostitutas dominicanas y rumanas (143). Un rasgo común es, no solo el carácter secundario de estas alusiones, sino el hecho de que estas figuras están sujetas a una focalización externa, están vistas desde los ojos de otro personaje o del narrador, y por ello carecen de voz propia.

En Diario de campo de Rosario Izquierdo, otra novela que podría enmarcarse dentro de la llamada "literatura de la crisis", la protagonista y narradora del relato observa a una mujer con un burka y especula sobre su situación sin que en ningún momento tengamos acceso al discurso o pensamientos de esta mujer musulmana. De una forma simbólica en cuanto a la separación entre esta narradora y este tipo de personaje, las puertas del autobús en el que la narradora viaja se cierran e impiden que esta se baje a hablar con la mujer del burka, como si las fuerzas internas del relato reforzaran la otredad y exclusión de este personaje. Aunque en ocasiones la representación de personajes inmigrantes es prácticamente inexistente, como en La habitación oscura de Isaac Rosa, existen también ejemplos de personajes secundarios con voz propia, como Ahmed en En la orilla de Rafael Chirbes, el exiliado uruguayo Marconi en Ajuste de cuentas de Benjamín Prado o varios de los personajes de Comité de la noche de Belén Gopegui, algo por otro lado natural al estar la acción de este último libro situada en Bratislava.

En este contexto queremos destacar 2020 de Javier Moreno, una novela que pone en el centro de su narración a dos personajes de origen extranjero: Nabil y Gowan. 2020 presenta un Madrid en el año 2020 desde la perspectiva fragmentada de varios personajes entre los que destacan: Gowan, escocés de segunda generación, un empresario millonario que ha desaparecido para ocuparse de la creación de un movimiento de resistencia; su hija, Josefina, una joven caracterizada por su anorexia y por su interés en los artículos de lujo; Jorge, un hombre obeso con síndrome de Asperger que ha perdido su trabajo en un laboratorio y se encuentra ahora trabajando en un bazar chino y viviendo en un avión abandonado; y Nabil, de origen saharaui también habitante del avión y elegido por Gowan para llevar a cabo su

\footnotetext{
${ }^{1}$ Los libros que constituyen el corpus de esta observación son principalmente En la orilla de Rafael Chirbes (2013), Panfleto para seguir viviendo de Fernando Díaz (2014), Los ciervos llegan sin avisar de Berna González Harbour (2015), El comité de la noche de Belén Gopegui (2014), Los besos en el pan de Almudena Grandes (2015), Democracia de Pablo Gutiérrez (2012), 2020 de Javier Moreno (2013), La trabajadora de Elvira Navarro (2014), Vente a casa de Jordi Nopca (2015), Ajuste de cuentas de Benjamín Prado (2013), Compro oro (2013a) y La habitación oscura (2013b) de Isaac Rosa.
} 
revolución. La acción arranca con la desaparición de Gowan, una figura mitificada y misteriosa, y durante el libro seguimos los pasos de estos personajes, todos ellos conectados con Gowan de alguna manera.

\section{Algunas consideraciones teóricas}

Nuestro análisis va a servirse de algunas nociones que queremos presentar aquí. Una de ellas es el no lugar de Marc Augé, y que Michelle Murrey retoma en su análisis de 2020. En su estudio Los no lugares. Espacios del anonimato. Una antropología de la sobremodernidad, Augé escribe: "Si un lugar puede definirse como lugar de identidad, relacional e histórico, un espacio que no puede definirse ni como espacio de identidad ni como relacional ni como histórico, definirá un no lugar" (83). En su libro, Augé asocia estos no lugares a "lo provisional y a lo efímero, al pasaje" (84), y nombra como ejemplos las cadenas de hoteles, los campos de refugiados, los clubs de vacaciones o los medios de transporte. Michelle Murrey retoma la noción de no lugar en su artículo "Capital Ruptures: Economies of Crisis and Urban Space in Javier Moreno’s 2020” (2016) para señalar la abundancia de no lugares en las páginas de 2020. Efectivamente, la acción de 2020 se desarrolla a menudo en una tienda, en un taxi, en una galería de arte, en un hotel, etc. Murray, sin embargo, va más allá, y explica cómo en la novela, Moreno "literally flips the script, imagining what happens when non-places that have heretofore operated in market interests are forced to broaden their functions to accommodate humanity" (77). Uno de estos no lugares convertidos en lugares es el avión abandonado en el que duerme Nabil junto con otros indigentes y que será objeto de un posterior análisis.

Otra noción relevante para el estudio del espacio en la novela es la heterotopía de Michel Foucault. En su texto "Of Other Spaces" Foucault contrasta la noción de utopía, que serían sitios sin un lugar real, "unreal spaces" $(1986,24)$, y la noción de heteropía, que se ve definida como un contra-espacio que representa e invierte los espacios reales: "something like countersites, a kind of effectively enacted utopia in which the real sites, all the other real sites that can be found within the culture, are simultaneously represented, contested, and inverted" (1986, 24). Foucault establece dos tipos de heterotopía. Por una lado está la heterotopía de la crisis: "privileged or sacred or forbidden places, reserved for individuals who are, in relation to society and to the human environment in which they live, in a state of crisis" $(1986,24)$. Un ejemplo de este tipo de heteropía, según Foulcault, sería el internado, donde los jóvenes adolescentes pueden desarrollan su virilidad lejos del hogar. Otra, tendría que ver con el rito de la desfloración y en este caso, Foucault nombra el viaje de novios y el espacio del hotel que alberga este acto (1986: 25). Según el teórico, las heterotopías de la crisis están desapareciendo y siendo substituidas por las llamadas heterotopías de la desviación, un lugar que contiene a individuos cuyo comportamiento difiere de la norma establecida (1986, 25), como por ejemplo un hospital psiquiátrico o una cárcel. En ocasiones, la crisis y la desviación se yuxtaponen, como en la heterotopía de los asilos de ancianos, ya que, como señala Foucault, la vejez se puede considerar una crisis en sí y, además, en una sociedad como la nuestra, la inactividad de la tercera edad es una forma de desviación. En un texto como el nuestro, interesado por el fenómeno de la crisis, la otredad y el espacio, la noción de heterotopía nos ayudará a profundizar en el estudio de 2020. 


\section{Crisis, desviación y heterotopía}

En 2020 encontramos alusiones rápidas a algunos personajes de origen extranjero como una prostituta tailandesa (82), otra eslava (220), la criada filipina de Josefina, a la vez que un buen número de reflexiones sobre la cultura china en los pensamientos de Jorge que ve a los chinos como un pueblo superior por su paciencia y materialismo. Más allá de estas alusiones, frecuentes también en otras novelas, queremos pararnos a analizar un personaje más central, Nabil, el retrato de su exclusión y la relación de esta con el espacio de la novela. Nabil, de origen saharaui, se mudó a Madrid de pequeño con su familia. Después de estudiar Filosofía, no logra encontrar trabajo y acaba empleado en un supermercado. Su movimiento final es a un espacio aún más liminal, el avión abandonado en el aeropuerto, un espacio entre naciones. Nabil parece empezar y acabar en espacios similares, del vacío del desierto del que viene al vacío de la llanura en la que se expande el aeropuerto, tal como él lo dice: "la meseta castellana, ese homenaje geográfico a la nada (38). Nabil parece condenado a vivir en la periferia de la que procede y su movimiento acaba devolviéndole a la casilla de salida.

El estudio del espacio, en particular del avión abandonado, es relevante para entender la otredad de Nabil. La descripción de este espacio resalta elementos no tan agradables:

Dentro del avión encuentro el mismo espectáculo de siempre: un puñado de cuerpos adormilados, arrebujados bajo mantas corporativas, como si se tratase de un grupo de supervivientes de una catástrofe aérea. Huele a aglomeración de cuerpos sucios. Huele a pobreza. Alguien eructa al fondo como saludo de bienvenida. El lenguaje de la miseria está hecho de gruñidos y monosílabos (20).

Esta escena, lejos de romantizar la pobreza, nos ofrece un panorama maloliente y sórdido. Aunque la ocupación del avión es ilegal, la presencia de mantas corporativas y la posterior mención de Nabil a la donación de botellas de agua por parte de compañías aéreas subraya un consentimiento tácito hacia este albergue improvisado. Nabil parece tener una posición privilegiada en el avión, que se plasma en el hecho de que éste, al menos en una de las escenas del libro, ocupa la cabina del piloto, la cual describe como su "santuario" (20) y en la que, al contrario que en el resto del avión, "Huele a limpio. Huele a riqueza" (21). Lo simbólico de la posición de Nabil al frente del avión se expresa de forma explícita en los pensamientos de este: "Me siento en el lugar del piloto para pensar en lo absurdo de la situación, en la extraña lotería de que Gowan me eligiera para acompañarlo al centro mismo del torbellino" (20). Tanto en Nabil como en el avión hay una contradicción interna. Ambos combinan lujo y pobreza, y ambos están desprovistos de la función que les tocaría desempeñar, en el caso de Nabil a causa del desempleo y en el caso del avión por encontrarse en desuso, abandonado en la periferia del aeropuerto. La posición de Nabil en la cabina de mandos de este avión oxidado y roto es por ello una imagen impactante y posiblemente reveladora en cuanto al futuro de su lucha junto a Gowan.

Michelle Murray ha destacado cómo el avión de 2020 invierte la noción de no lugar de Marc Augé con la cual el teórico describe lugares de tránsito intercambiables y asociados frecuentemente al consumo. El avión es un no-lugar típico ya que sirve a la vez como espacio de tránsito y para el tránsito. El avión de 2020, sin embargo, es un lugar de tránsito convertido en un lugar de residencia y, tal como Murray menciona, de esa manera es un no lugar "reconvertido en un lugar" (2016, 85, mi traducción) ${ }^{2}$. Si la noción de no lugar de Augé nos

\footnotetext{
${ }^{2}$ En el original de Murray leemos: "As a non-place now used to shelter the homeless and, hence, reverted back
} into a place, the plane reeks of sheer humanity" $(2016,85)$ 
sirve para ilustrar la inversión de ciertos espacios en esta novela, la noción de heteropía de Foucault permite asociar el estudio del espacio con las dos variables que sirven de base a este estudio: la crisis y la diferencia. En el apartado de consideraciones teóricas, mencionamos la noción de heterotopía de Michel Foucault y vimos cómo Foucault, en su texto "Of Other Spaces", establece dos tipos de heterotopía. La primera es la heteropía de la crisis que Foucault ejemplifica haciendo referencia a circunstancias más intrínsecas al ser humano como la adolescencia o la vejez. Llevada, sin embargo, a la esfera de lo social, la noción de heterotopía de crisis refleja a la perfección la descripción del avión de 2020, repleto de personajes en una doble crisis, la personal y la global.

El otro tipo de heterotopía que establece Foucault es de la desviación, un lugar que contiene a individuos cuyos comportamientos difieren de la norma establecida $(1986,25)$. El avión que presenta 2020 es un espacio donde se refugian personajes que por diferentes razones no tienen un lugar dentro del sistema socio-económico imperante. La novela nos presenta a varios habitantes del avión y lo común a la mayoría de estos es que se encuentran sin trabajo. En una sociedad basada en la producción y en el consumo, como la de la novela, como la nuestra, la pérdida del trabajo y la posterior pérdida de la vivienda, conlleva una desviación y una otredad. A nivel personal, los personajes que habitan el avión representan otros tipos de diferencia: de orden racial, en el caso de Nabil, y de orden neuropsiquiátrico en el caso de Jorge, el personaje Asperger. El avión cumple la función de cobijar a estos personajes pero también de separarlos del resto de la sociedad, función que Foucault asocia a las heterotopías y, en este sentido, no es extraño que el avión se encuentre en esta zona periférica y difícilmente accesible a través de un agujero de una valla. Otra de las características que Foucault asocia a la heterotopía es la yuxtaposición en un lugar de diversos lugares incompatibles $(1986,25)$ y el avión que habita Nabil fusiona, sin duda, dos realidades opuestas: la abundancia asociada al viaje de avión y la austeridad de la indigencia; la riqueza y la miseria; el ocio y la supervivencia; el pasado y el presente.

Este avión abandonado, junto con otros, en las pistas de la T4 de Barajas se puede relacionar con dos heterotopías que Foucault expone en su texto: el museo y el cementerio. El avión, inservible y anticuado, se puede ver como una pieza de un museo improvisado, un museo al aire libre sin más visitantes que sus moradores. A su vez, este avión desechado, junto con otros, forma parte de una especie de cementerio de aviones forjado por la crisis y un cálculo de costes que ha visto en este abandono la opción más asequible para deshacerse de un avión deteriorado. De forma paralela, las vidas de sus habitantes, en particular la del personaje que nos ocupa, Nabil, podría verse también como el producto de un cálculo, que mantiene a una parte de la población en la precariedad. El final de la novela, en el que Jorge, el personaje Asperger explotado en una bazar chino, entra en una performance con un rifle, es relevante en este respecto. Aunque Jorge parece cegado por la ira y la locura, lo cual se pone de manifiesto en la descripción de este con los "ojos inyectados en sangre" (255), finalmente, este redirige el cañón de su rifle desde Nabil, su compañero de miserias, hacia Gowan, el representante en el libro de la élite, del éxito en el sistema socio-económico vigente. Nabil y Jorge comparten no solo el espacio del avión, sino también una crisis y una otredad, y la elección final de Jorge podría verse como un eco de la visión de Gowan de una sociedad futura en la que "los descastados" se vengan de sus explotadores. 


\section{Sin poder, sin herencia}

Nabil ha luchado gran parte de su vida con el objetivo de salir de la pobreza y su viaje, que traza una línea circular, es representativo de esta lucha tenaz pero infructífera. A pesar de que Nabil es un constante desposeído, no se rinde en su búsqueda de cambio: "Él no había poseído nunca nada $\mathrm{y}$, sin embargo, lucha denodadamente por encontrar algo que yacía escondido en algún lugar, esperándolo" (183). Nabil parece así tener un destino final, este espacio escondido, en el que se encuentra ese "algo" que lo espera, y que con la elección de la palabra "algo" denota indefinición y duda. Las esperanzas y la meta de Nabil se ven como algo a la vez muy real y muy borroso, algo que pertenece a un futuro incierto. Hay que destacar el aspecto temporal de la lucha de Nabil y la división que él mismo hace entre un pasado desgraciado pero ante el cual Nabil adquiere cierto poder y un presente en el que se encuentra indefenso: "El pasado es una larga secuencia de desgracias y, sin embargo, puedo hacerme fuerte en él, puedo vallarlo y erigirme propietario del estercolero de la memoria. El presente en cambio es la intemperie, el desamparo de esta cabina contra la que golpea el frío" (21). El presente de Nabil es un presente de lucha pero de una lucha sin poder, una lucha supeditada a la voluntad de Gowan, el otro protagonista de la novela, un hombre que ha desaparecido de su casa y se encuentra escondido planeando una revolución descrita de forma confusa en la novela. Desde su inicio, esta colaboración se establece partiendo de la voluntad de Gowan ya que es este el que elige a Nabil para su proyecto.

La interacción entre estos dos personajes pone en evidencia un desequilibrio de poder constante entre ellos. Las acciones de Nabil quedan supeditadas a la voluntad de Gowan, que decide cuándo y dónde se van a encontrar y qué van a hacer. La comunicación entre estos dos personajes sigue una línea parecida con largas intervenciones de Gowan, en las cuáles expone sus ideas, y pequeños incisos de Nabil para hacer alguna pregunta sobre algo que no entiende o para responder brevemente alguna petición de Gowan. A menudo, las intervenciones de Gowan asemejan monólogos por su extensión y por su hermetismo, que refleja una aparente falta de consideración con respecto a su interlocutor. Nabil adquiere así el papel de ayudante sumiso y se convierte en un personaje no solo subyugado sino también expuesto a la humillación, algo de lo que es consciente: "Soy [...] una mascota a la que su dueño devuelve a la perrera" (20).

Gowan es descrito tanto en su propio discurso como en el de otros personajes de la obra como un ser superior al que es difícil comprender ${ }^{3}$. A sí mismo se describe como "El primer ejemplar de una raza nueva" (43) y a Nabil le dice: "Soy mortalmente bello. [...] Mi reino, Nabil, no es de este mundo". El propio Nabil se lo imagina como "un dios fundador de una nueva religión" (112). A la vez que Gowan expresa esta superioridad desvela su fascinación por lo que él llama "los descastados" (96). Nabil está incluido en este grupo y la fascinación de Gowan hacia él es contradictoria: "Te amo. Te odio. Me desvelo ante ti para que aprendas mi naturaleza, para que los nietos de tus nietos tengan alguna posibilidad, un objeto para su furia. Todos deseamos crear una máquina que sea capaz de derrotarnos" (97). Nabil sería así pues esta máquina, esta creación de Gowan, cuyos planes de revolución parecen basarse en una lucha de clases según la cual, los más desfavorecidos, encarnados en Nabil, deberían derrotar a los más poderosos, como Gowan. Gowan adquiere así rasgos suicidas a la vez que Nabil coquetea con la posibilidad de erradicar a Gowan. La balanza de poder parece momentáneamente moverse con ayuda del factor violencia y esto se puede ver en la escena en la que Gowan regala

\footnotetext{
${ }^{3}$ Uno de los personajes de la novela, Lázaro, lo describe como "un ídolo ante el que uno se humilla" (54) y Josefina, su hija, dice "mi padre hacía el trabajo de Dios" (166).
} 
un cuchillo a Nabil y le insinúa la posibilidad de matarle. La escena, que se desarrolla en un taxi, está focalizada en torno a los pensamientos de Nabil que muestra extrañeza ante tal posibilidad: "No sabría qué hacer con él, salvo herirme a causa de mi torpeza" (204). Durante el trayecto en el taxi sin embargo, Gowan destaca la inferioridad de Nabil hasta el punto que Nabil empieza a jugar con la idea de matar a Gowan: "Miro de nuevo el puñal. Bastaría un leve impulso" (207). Gowan finalmente zanja el asunto, una vez más, con un imperativo y desmonta la posibilidad de un asesinato tomando de nuevo las riendas de la situación: "Ahora puedes guardar eso. He decidido que ya no me apetece morir. Quiero divertirme” (207).

Nabil parece así expuesto a una total carencia de poder incluso en una situación, la lucha política, cuyo objetivo debería ser el contrario, la adquisición de poder. Su otredad se ve claramente expresada en el discurso de Gowan, "Te delata tu origen, tu clase" (206), pero también en la autopercepción del propio Nabil. Una escena reveladora en cuanto a esto es el momento en el que Nabil se encuentra en la pista del aeropuerto, cerca del avión abandonado en el que vive. Gowan le ha comprado una serie de artículos de lujo y su posición en este lugar de miseria en combinación con su indumentaria crean una peculiar estampa:

Bastante sospechoso resulta el hecho de que un saharaui que no tiene dónde caerse muerto vista un traje de Armani. La pista está helada. Extiendo los brazos para buscar el equilibrio. Los Vuitton no fueron diseñados para caminar sobre el hielo. Imagino a uno de los sin techo asomado a la ventanilla, frotándose los ojos ante la irrealidad de la escena: un hombre vestido con traje de ejecutivo se desliza hacia un avión abandonado. (19)

Nabil se siente observado aunque realmente, nadie le está mirando sino que él "imagina" que alguien le percibe como a un elemento extraño. La sensación de sospecha que vemos en la cita es así pues producto de una construcción mental del propio Nabil concretizada en la mirada imaginada de otra persona.

El espacio, es aquí un elemento fundamental. Por una parte, es su posición en las pistas de aterrizaje, al lado de este avión poblado por indigentes, junto con su vestimenta, lo que crea la sensación de otredad y sospecha. Por otro lado, Nabil parece no tener un espacio propio, ya que incluso en este espacio en el que se aloja, junto a personajes en su misma situación de precariedad, éste se imagina diferente y excluido, a través de una autopercepción que, como hemos visto, lo convierte en sospechoso. La noción de "literatura de los desheredados" de Pablo Valdivia, que tan bien describe la sensación de pérdida de un buen sector de la población española nos sirve para entender mejor el personaje de Nabil, que dejos de ser un personaje desheredado es un personaje privado de promesas y de futuros ciertos o inciertos. A pesar de ser un personaje golpeado por la crisis, no nos encontramos ante un personaje desheredado ya que Nabil nunca tuvo una expectativa de herencia. Esta es quizás una de las claves para comprender la otredad y la exclusión de este personaje. A otros rasgos de otredad, como los rasgos físicos o el origen extranjero, se une el hecho de que Nabil nunca tuvo una promesa de futuro. 2020 aúna así el relato de una realidad más amplia, la de la crisis y sus consecuencias, con el de la experiencia de otredad y exclusión más absolutas de un personaje que no posee nada y que, a pesar de una lucha constante, se mueve en círculos.

\section{5. Últimas consideraciones}

La novela 2020 presenta a un personaje inmigrante, Nabil, desde la perspectiva de sus pensamientos, sus acciones y su localización en espacios que en ocasiones simbolizan tanto su 
lucha como su falta de poder. Nabil se describe como un personaje dinámico pero cuyos pasos parecen tener un carácter circular que le devuelven a la posición de exclusión de la que proviene, siendo su tránsito en el tiempo y espacio más un retroceso que un avance. Nabil se encuentra inmerso, junto a Gowan, en una lucha pero incluso en ésta, se ve desprovisto de poder, sumiso en incluso humillado por Gowan. El avión en el que habita junto a otros indigentes es representativo de varios aspectos en relación a este personaje. Por una parte, su posición en la cabina del piloto, refleja su otredad en relación a los otros residentes en la nave pero también la imposibilidad de éxito que sugiere la estructura oxidada e inoperativa del avión. Por otra parte, Nabil, situado en las pistas de aterrizaje, imagina una mirada de sospecha y extrañeza que desvela su autopercepción como diferente. El avión es además un buen ejemplo de la inversión de ciertas estructuras en torno al personaje de Nabil y, en ese sentido, hemos visto como el avión es un no lugar típico convertido en lugar, tal como comenta Michelle Murray, un lugar de tránsito convertido en lugar de residencia. El avión de 2020 es además un buen ejemplo de heterotopía y yuxtapone las dos nociones que Foucault destaca en relación a esta noción: crisis y desviación. El avión que habita Nabil está repleto de personajes afectados por la crisis económica, una crisis global que, a su vez, cristaliza en las diferentes crisis personales de los personajes. Los habitantes del avión son, por otra parte, representantes de diferentes tipos de desviación (por su origen, por sus desórdenes neuropsiquiátricos, por su situación de desempleo, etc.) y la función de esta heterotopía es doble ya que aloja pero también aísla, manteniendo a estos personajes alejados del resto de la sociedad. Nos encontramos sin duda con una novela que, rompiendo los moldes de gran parte de la literatura contemporánea sobre la crisis, pone a Nabil, un personaje de origen no español, en el centro de su narración haciendo así un relato sobre la desposesión, la otredad y la lucha por moverse más allá de la casilla asignada.

\section{Bibliografía}

Augé, Marc. 2000. Los no lugares. Espacios del anonimato. Una antropología de la sobremodernidad. Barcelona: Gedisa.

Becerra, David. 2015. "Introducción”. Convocando al fantasma. Novela crítica en la España actual. Madrid: Tierradenadie Ediciones.

Celaya-Carrillo, Beatriz. 2011. "Pánicos racistas: reflexiones sobre la inmigración en Cataluá y España a partir de un texto de Najat El Hachmi” MLA, 126 (2): 344-365.

Chirbes, Rafael. 2013. En la orilla. Barcelona: Anagrama.

Díaz, Fernando. 2014. Panfleto para seguir viviendo. Madrid: La Oveja Roja.

Foucault, Michel. 1986. "Of other Spaces". Diacritics, 16 (1): 22-27.

González Harbour, Berna. 2015. Los ciervos llegan sin avisar. Barcelona: RBA.

Gopegui, Belén. 2014. El comité de la noche. Barcelona: Random House.

Grandes, Almudena. 2012. Los besos en el pan. Barcelona: Tusquets.

Gutiérrez, Pablo. 2012. Democracia. Barcelona: Seix Barral.

Moreno, Javier. 2013. 2020. Madrid: Lengua de trapo.

Murray, M. 2016. "Capital Ruptures: Economies of Crisis and Urban Space in Javier Moreno's 2020”. 452 F : Revista de Teoría de la Literatura y Literatura Comparada, 15: 71-92. 
Navarro, Elvira. 2014. La trabajadora. Barcelona: Penguin Random House.

Nopca, Jordi. 2015. Vente a casa. Barcelona: Libros del Asteroide.

OECD International Migration Outlook. 2014. OECD Publishing. Acceso 5 octubre 2017: http://dx.doi.org/10.1787/migr_outlook-2014-en

Prado, Benjamín. 2013. Ajuste de cuentas. Madrid: Alfaguara.

Rodríguez Marcos, Javier. 2013. «Una crisis de novela». El País, 16 de Marzo.

Rosa, Isaac. 2013a. Compro oro. Madrid: La marea.

Rosa, Isaac. 2013b. La habitación oscura. Barcelona: Seix Barral.

Valdivia, Pablo. 2016. "Narrando la crisis financiera de 2008 y sus repercusiones". $452^{\circ} F$ : Revista de Teoría de la Literatura y Literatura Comparada, 15: 18-36. 